\title{
Agustina Bessa-Luís: a força do romance como enciclopédia aberta e o ímpeto arquivístico
}

\section{Agustina Bessa-Luis: The Strength of the Novel as an Open Encyclopedia and Archival Impetus}

\author{
Rodrigo Valverde Denubila \\ Universidade Federal de Uberlândia (UFU), Uberlândia, Minas Gerais / Brasil \\ rodrigo.denubila@ufu.br \\ https://orcid.org/0000-0002-4935-303X
}

Resumo: Este artigo analisa a obra de Agustina Bessa-Luís (1922-2019) pela concepção de romance como enciclopédia aberta, conforme propõe Italo Calvino em Seis propostas para o próximo milênio. Inicialmente, discorremos sobre a Encyclopédie iluminista. $\mathrm{Na}$ sequência, dialogamos com a fortuna crítica da escritora portuguesa e com os estudos acerca do romance como enciclopédia aberta para justificar o caminho de leitura empreendido. Apontamos também o caráter arquivístico e inventariante qualificador do romance enciclopédico. Trabalhamos com as ponderações teóricas de Italo Calvino (1990), Maria Esther Maciel (2009), Maria das Graças Souza (2015) e Umberto Eco (2013).

Palavras-chave: romance como enciclopédia aberta; enciclopedismo; Agustina BessaLuís.

Abstract: This article analyzes the work of Agustina Bessa-Luís (1922-2019) by the conception of romance as an open encyclopedia, as proposed by Italo Calvino in Six proposals for the next millennium. Initially, we talked about the Enlightenment Encyclopédie. Next, we dialogue with the portuguese writer's critical fortune and with the studies about the novel as an open encyclopedia to justify the reading path undertaken. We also point out the archival and inventoried character that qualifiers the encyclopedic novel. We work with the theoretical weightings of Italo Calvino (1990), Maria Esther Maciel (2009), Maria das Graças Souza (2015) and Umberto Eco (2013).

Keywords: novel as an open encyclopedia; encyclopedism; Agustina Bessa-Luis. 


\section{Introdução}

António M. Feijó, João R. Figueiredo e Miguel Tamen (2020) publicaram recentemente o volume $O$ cânone. Ao fazerem a seleção dos escritores consagrados, incluíram o nome de Agustina Bessa-Luís. A ordem alfabética determina a organização dos verbetes, constando duas exceções: Camões e Fernando Pessoa, escritores que abrem e fecham a coletânea. Esses escritores também possuem dois verbetes cada.

$\mathrm{Na}$ abertura do livro, deparamo-nos com o verbete de Agustina Bessa-Luís seguido pelo de Alexandre Herculano, nome-chave da historiografia portuguesa. Apesar da organização alfabética, é interessante pensar que Camões, Fernando Pessoa, Agustina BessaLuís e Alexandre Herculano formam notável quadratura epistêmica de autores que escrevem e literariamente pensam ethos de Portugal à medida que levantam e inventariam aspectos da história e da cultura lusa. Na História da literatura portuguesa, Óscar Lopes (1982, p. 346, grifos nossos) sublinha o caráter enciclopédico de Os Lusíadas: "Camões não quis apenas fazer uma enciclopédia histórica, mas também uma enciclopédia naturalista, contrapartida quanto possível real do antigo maravilhoso homérico".

O ímpeto enciclopédico igualmente guia Agustina Bessa-Luís e, por essa razão destacamos que são dois os principais objetivos que orientam esta reflexão. Primeiro, relacionar aspectos extra e intralilerários que nos permitem analisar a poética do romance como enciclopédia aberta, de acordo com a terminologia estabelecida por Italo Calvino (1990), em Seis propostas para o próximo milênio. Segundo, perspectivar a obra agustiniana com base na concepção de romance como enciclopédia aberta. Em vista disto, em nosso percurso, investigamos pontos da poética do romance como enciclopédia aberta para tracejarmos algumas das razões de se compreender a obra de Agustina Bessa-Luís como enciclopédica. Tece-se discussão de caráter geral, oferecendo uma forma de compreensão do conjunto literário agustiniano como enciclopédico, não de um romance em específico.

\section{Poética do romance como enciclopédia aberta}

No século XVIII, Denis Diderot e D'Alembert estruturam a Enclycoplédie a partir de três áreas do saber: a Filosofia, a História e a 
Estética. A Filosofia se espraia na razão como mecanismos para explicar o mundo sensível e o suprassensível, na medida em que ela funciona como "referencial de orientação do homem" (ABBAGNANO, 2012, p. 969).

Em relação à História, faz-se necessário distingui-la da historiografia. Ou seja, assinalar a diferença entre acontecimentos e escrita desses, logo, como o pretérito se faz acessível por meio de textos, como acontecimentos ganham textualidades e discursos heterogêneos, $o$ que assinala o multiperspectivismo. Este consiste em uma das dinâmicaschave estruturantes do romance como enciclopédia aberta enquanto fator intensificador da multiplicidade. Adquire força as múltiplas percepções de como os seres leem a realidade. A História intersecciona-se com a historiografia. Esta, como recurso linguístico, pode dar azo à ficção.

A criação estética relaciona-se com a sensibilidade individual à medida que se torna responsável pela construção plástica. Criação e construção plasmam a visão do artista sobre a existência (ABBAGNANO, 2012, p. 427). A estética ancora-se na filosofia; todavia, existe também a impossibilidade de fechamento em uma apreensão de caráter universalista.

Há o estrato que reflete sobre a História e sobre a memória, mas há semelhantemente o espaço para a reflexão sobre a poiesis, que é o estrato que fomenta o discurso teórico dentro do discurso ficcional. Este é um elemento importante do romance como enciclopédia aberta, visto que a multiplicação de níveis e de gêneros textuais, no espaço de uma mesma obra, produzem a variação de pontos de vista, mas igualmente a sensação de instabilidade, já que a multiplicação conduz ao incerto. Tradicionalmente, as reflexões de natureza filosófica, estética e histórica possuem o intuito de delimitar o certo, visando a uma perspectiva universalista e, então, ao modo como o mundo, em sua totalidade, deve ser lido por uma verdade, o que essencialmente nega a multiplicidade. Logo, se há uma linha de pensamento preponderante guiada por um saber, que passa a ser visto como o saber, este guarda consequentemente o sentido final da existência pela fixação dos valores de um grupo como a verdade de todos e o sentido final da existência.

Além desses três campos, a organização da enciclopédia iluminista ocorre em outras duas frentes. Como referido, primeiro, nas áreas de sustentação (filosofia, história e estética); segundo, nos seus objetos, isto é, no inventário e no arquivamento dos saberes cuja intenção era vencer a ação temporal e provocar melhora social pelo acesso ao conhecimento; terceiro, inovações estruturais. Neste último campo, uma das grandes 
novidades da Encyclopédie encontra-se no seu índice remissivo. Este faz com que o leitor, depois da descrição de um verbete, seja jogado à leitura de outro que complementa ou nega a informação que acabou de ser lida. O movimento ocorre sucessivamente e gera o puzzle de informações. Quebra-se dessa forma com a lógica monolítica do saber ao passo que se destaca a configuração incompleta do conhecimento inventariado.

Com essa dinâmica, quem consulta uma enciclopédia lida com um mosaico de elementos. Os mecanismos obrigam que cada leitor estabeleça a "unidade" por si só, crie o seu sistema lógico que transforma fragmentos de informação em unidades de informação. Conectar um ponto a outro, quer para afirmar, quer para negar, fica a cargo do leitor, que lida com a multiplicidade e com a extensa carga de informação típica da enciclopédia. Existe, portanto, uma importante inovação estrutural que também manifesta, além grandeza de conhecimentos, a aleatoriedade de toda classificação, sendo este um dos traços significativos do romance como enciclopédia aberta, segundo Maria Esther Maciel (2009), em As ironias da ordem. Ao adotar o índice remissivo, descontinuidades estruturam a enciclopédia e criam uma "rede multidimensional de elementos discretos que se podem ligar, articular, aproximar de acordo com relações múltiplas, contatos flutuantes, curto-circuitos instantâneos, em perene mutação", de acordo com Olga Pombo (2006, p. 187), em $O$ círculo dos saberes. Acrescentando vozes a essa discussão, em "Dicionários versus enciclopédia", Umberto Eco (1991, p. 113) atenta para o fato de que "a enciclopédia como totalidade das interpretações contempla também interpretações contraditórias". O contraditório representa um dos aspectos estruturantes da enciclopédia. Por essas sendas, reconhecemos como a multiplicidade acentua as contradições atravessam o ser humano. Este mergulhado em um universo ininteligível, "sem conexões estáveis e evidentes, não-sintetizáveis" (LOPES, 1990, p. 111), logo, apartados de totalidades e de retilíneos caminhos, como se estivessem em um labirinto.

No "Discurso preliminar", abertura da Encyclopédie, Jean le Rond d'Alembert (2015) reconhece o caráter labiríntico, incompleto e tortuoso do projeto enciclopédico. Nesse sentido, "a enciclopédia é um conjunto não ordenado (e potencialmente contraditório) de marcas” (ECO, 1991, p. 133). Daí, consequentemente, a abertura semântica como fenômeno ocasionado pela multiplicidade de cadeias relacionais e pelas contradições possíveis construídas pelo índice remissivo. Quando comenta a estrutura 
aberta da enciclopédia iluminista, o referido filósofo francês demarca a construção de um quadro multidimensional - mapa esse feito pela importante inovação estrutural do índice remissivo. Com essa afluência, sedimentam-se a estrutura em teia de sentidos qualificadoras do romance como enciclopédia aberta. A rede enciclopédica interconecta tempos, espaços, objetos, pessoas e saberes que se dilatam constantemente, conforme identifica Italo Calvino (1990, p. 126): “A rede que concatena todas as coisas [...] é feita de pontos espaço-temporais ocupados sucessivamente por todos os seres, o que comporta uma multiplicação infinita das dimensões do espaço e do tempo. $\mathrm{O}$ mundo dilata-se a tal ponto que se torna inapreensível".

Ao levantar e inventariar saberes, a linguagem ganha centralidade e força, pois o processo revisionista, multifacetado e problematizador empreendido por autores enciclopédicos cai na apreciação acerca da natureza dessa. A linguagem dá sustentação aos discursos filosóficos, estéticos e historiográficos. É por meio dela que perspectivas e conhecimentos são estabelecidos. Representa fator de coerências que a reflexão crítica de Agustina Bessa-Luís passe pelas considerações acerca da linguagem, conforme se pode inferir a partir de fragmentos como este:

O homem é um ser velado e obscuro. Só o outro o pode interessarse na linguagem e, assim, levá-lo a revelar-se. Mas a linguagem é apenas fonética? São apenas sinais e sons? Não. A linguagem é um meio de fixação do homem à sua realidade. Ela é tanto mais um problema da decisão humana, quanto está na raiz do destino social. (BESSA-LUÍS, 2000, p. 65)

A investigação da linguagem dá espaço à elucubração acerca do sentido do ser e sobre a construção dos saberes, bem como guarda um valor de coleta. Os filósofos Denis Diderot e d'Alembert partem do pressuposto da necessidade de recolha do máximo de componentes, pois "no caso da Enciclopédia, trata-se sobretudo da conservação e da transmissão dos conhecimentos produzidos pelo homem, dos mais variados tempos e lugares" (SOUZA, 2015, p. 19). Sublinha-se, nesses termos, a perpetuação no tempo da ideia de conservação, pois a enciclopédia tinha como objetivo fazer com que os saberes fossem preservados da destruição temporal.

Em Mutações da literatura no século XXI, Leyla PerroneMoisés (2016, p. 110) assinala que tal aspiração consiste em um dos 
imperativos mais evidentes da produção atual: “"Preservar' é uma das palavras mais frequentes nos ensaios dos romancistas contemporâneos". $\mathrm{Na}$ coletânea de ensaios $O$ romancista ingênuo e o sentimental, Orhan Pamuk (2011) escreve o capítulo "Museus e romances" para refletir acerca da necessidade de preservar que o escritor sente, entendendo-a como uma tentativa de lutar contra o aumento da sensação de efemeridade e homogeneização causadas pelo império do efêmero. De acordo com o autor e ensaísta turco, uma parte dos romances contemporâneos deseja exatamente "preservar costumes, atitudes e estilos de vida" (PAMUK, 2011, p. 95), além de inventariar espaços e objetos para "preservar, conservar e resistir ao esquecimento" (PAMUK, 2011, p. 98).

No ensaio Hiperculturalidade, Byung-Chul Han (2019) marca como o momento do capitalismo do bit, dos grandes conglomerados tecnológicos, fomenta a quebra da concepção de pertencimento à medida que se plasma uma cultura de excessos. A digitalização da existência transforma identidades, relações afetivas e concepções de nação. Ao mesmo tempo, mas em grandeza inversa, cria-se o desejo de salvaguardar as coisas do mundo frente a um contexto histórico que desmaterializa experiências. Um tempo atual marcado por excessos fomenta romances igualmente excessivos, como baliza Leyla PerroneMoisés (2016, p. 170), em Mutações da literatura no século XXI, ao assinalar a volta do "romanção". Isto é, romances exigentes, grandes, complexos, formados por muitas tramas e subtramas. Nas obras de cunho enciclopédico, há, portanto, demasiadas informações e conteúdos que impõem ao leitor a obrigação de enxergar e de estabelecer inúmeras redes de sentido. Diferentes pontos formam o rizoma qualificador do romance como enciclopédia aberta. Cabe sublinhar que tal dinâmica não precisa necessariamente estar presente dentro de um mesmo livro, mas sim no conjunto literário do autor ou em ambos os casos. Uma obra enciclopédica não significa que a toalidade o seja, assim como textos literários não marcados pela configuração do romance como enciclopédia aberta podem, na sua horizontalidade, fomentar o aspecto enciclopédico do conjunto, como acontece com o angolano Pepetela.

Além do arquivamento de conhecimentos, há também outro desejo qualificador da Encyclopédie: frisar a capacidade emancipatória do saber. Por isso, quando discute a importância da enciclopédia, Maria das Graças Souza (2015, p. 25) a vê como algo tipicamente moderno: 
Não apenas fiel ao movimento iluminista, mas sobretudo como sua maior manifestação, a Enciclopédia sustenta a convicção de que homens instruídos são melhores e mais virtuosos. A instrução, libertando os homens da ignorância, liberta-os também do preconceito, do fanatismo, da superstição e da violência. Nas palavras de Soboul, "as luzes construíram uma etapa decisiva do pensamento libertário, e a Enciclopédia permanece como um documento grandioso".

A substância moderna presente na enciclopédia iluminista não está apenas na totalização dos saberes, mas principalmente no poder de libertação através do conhecimento entendido como esclarecimento. Sobre a crença no caráter progressivo do saber, argumenta Nicola Abbagnano (2012 p. 971) que "a razão teria a tarefa de agir sobre o ambiente para promover formas de vida mais satisfatórias e perfeitas". Identifica-se, dentro do ideário iluminista e, em maior grau, do mundo moderno e da modernidade, a capacidade da razão de ser o guia "constante, uniforme e (às vezes) infalível de todos os homens, em todos os campos da atividade destes" (ABBAGNANO, 2012, p. 971).

Constantemente em busca de e dando sentidos às coisas, os seres arquitetam cadeias interpretativas que formam, em espectro maior, redes rizomáticas distributivas. Começa-se então a formar a percepção de uma estruturação em rede. Em "O ornitorrinco entre dicionário e enciclopédia", Umberto Eco (1998, p. 195) distingue que o gesto interpretativo se dá a partir da percepção do "conjunto de propriedades" indispensável dos seres e dos objetos. Em outro momento, o pensador italiano classifica a enciclopédia como "rede de interpretantes" (ECO, 1991, p. 140). Ao investigar o significado do significado, o autor intitula as dinâmicas complexas da mente de semânticas enciclopédicas, ou melhor, de "semântica com formato de enciclopédia" (ECO, 1991, p. 74). Se o dicionário oferece representações estruturadas e condições estáveis, a enciclopédia desfragmenta e abre rizomas.

Os intérpretes constroem conceitos sobre tudo e todos, marcando suas existências na medida em que o espírito precisa de cadeias significativas para formar conexões. Por esse motivo, segundo Umberto Eco (1991, p. 126), a enciclopédia contemporânea consolida-se como "o registro de todos os possíveis interpretantes do termo analisado e de todas as relações contextuais e circunstanciais". Após o conceito ser internalizado, torna-se praticamente impossível a mente olhar de forma 
neutra para algo, pois os seres buscam inconscientemente esse "algo" como "algo", posto que expressão sem referência significa expressão sem sentido. Sabemos, por exemplo, que saída é saída, que livro é livro, por meio da decomposição destes em significados que se conectam a redes semânticas. Tal acontece sem que se tenha que buscar o sentido sempre de modo consciente. Portanto, "o significado lexical deve ser mais complexo do que a associação de uma expressão com algumas propriedades excepcionais e deve ser entendido como a associação de uma expressão com uma série de instruções para o uso em contextos diferentes" (ECO, 1991, p. 73-74). Cabe, desse modo, interrogar: como mudar a maneira pela qual os sentidos se ligam a algo e são transformados em linguagem?

A estrutura em rede rizomática distributiva exemplifica a dinâmica do intelecto, mas também do romance como enciclopédia aberta. Ter uma arquitetura entrelaçada significa apreender como o excesso de informações e a mudança de sentidos prévios são capazes de criar rizomas. Frisa-se o vislumbre de como entes estão conectados por cadeias complexas. Uma das linhas de força da multiplicidade constitutiva do romance como enciclopédia aberta é fazer com que o leitor busque novas redes relacionais em razão da alteração semântica. Nos romances enciclopédicos, círculos se conectam, se diferenciam e se complementam a ponto de fomentar à percepção do método de amplificação maximalista e hiperbólico. A competência enciclopédica vincula-se à capacidade de estabelecer caminhos, visto que comunicar não se reduz a dizer algo, mas a levantar conexões entre as coisas, pessoas, tempo, espaço e objetos distintos. Esse ato manifesta as coisas do mundo por intermédio de pontos-rizomas que formam teias e entrelaçamentos. Saberes, linguagem, interpretações e alterações sócio-históricas constituem, portanto, os dados significativos encontrados até então e vão se ampliando de forma maximal à medida que abalam convenções. Em "Da árvore ao labirinto", Umberto Eco (2013, p. 58) chama esse sistema aberto de liames de enciclopédia maximal, haja vista que "nesse sentido, a enciclopédia é potencialmente infinita porque é móvel, e as análises que fazemos sobre sua base a recolocam continuamente em questão".

Uma das perguntas-chave, vista como responsável pelo exercício enciclopédico, pode ser encontrada na indagação acerca da maneira pela qual as verdades e os conhecimentos são construídos, difundidos e aceitos. Isto, inclusive, está na avaliação do romance como enciclopédia 
aberta, como método de conhecimento. Colocar saberes em xeque significa entender a História enquanto teia de associações, não como narrativa hierárquica, retórica e linear. Vê-la desse modo significa enxergá-la como hipertexto, como bem sublinha Carlos Ceia (2007, p. 45), em A construção do romance: "A História é hipertextual, porque cada facto passado abre para um momento de reflexividade".

$\mathrm{O}$ romance como enciclopédia aberta inventaria, repensa, além de problematizar diferentes formas de conhecimentos, o que corporifica a dúvida elementar, entre elas, a que se espraia sobre a História. Tanto o excesso como o vazio são forma distintas para qualificar a mesma coisa, isto é, a quebra de teleologias. Em vista disso, cabe ressaltar a maneira como Milan Kundera (2016, p. 14) argumenta que, com as transformações pelas quais a literatura passou, "a única Verdade divina se decompôs em centenas de verdade relativas que os homens dividiram entre si".

O repensar, o repaginar, a inclusão e a "assimilação de paradoxos e limitações" (FERNANDES, 2011, p. 43) levam à multiplicação e refutam "a integração do saber humano numa ordem e numa forma de densidade estável" (CALVINO, 1990, p. 131). A materialização do paradoxo e da multiplicidade surge na tessitura textual. Não há um desejo de exclusão, nem de escolha de um aspecto em específico pela semântica de cariz enciclopédia, como postula Umberto Eco (1991). Muda-se a conjunção alternativa para a aditiva. Na não seleção, a tentativa de abranger o mundo em sua complexidade resultam na "inclusão" e na "assimilação". Essas atitudes são importantes ao período que pode ser classificado de pósmoderno, bem como ao romance que contém traços pós-modernistas e ao romance como enciclopédia aberta.

Quando se estabelece a força da adição, em igual medida, apontase para a indeterminação, uma vez que na acumulação de predicados há igualmente uma abundância de referências, logo, maior indeterminação nascida do aumento e do armazenamento das diversas interpretações responsáveis por criar a cadeia semântica que conecta coisas e pessoas. Seguindo essa ordem de ideias, Italo Calvino (1990, p. 131) sublinha: "Hoje em dia não é mais pensável uma totalidade que não seja potencial, conjectural, multíplice". Percebemos o desenvolvimento desse raciocínio, quando referenciamos as áreas do conhecimento vistas pela ótica da enciclopédia, ou quando interpelamos a construção da narrativa de uma vida pela recolha das ruínas do ser. Por ângulos diversos, o não fechamento ganha notoriedade e as forças compositivas e estruturais do romance como enciclopédia aberta se conectam. 
No ensaio "Dicionário Kazer: as múltiplas leituras de um texto ou a construção/desconstrução da obra literária", Aleksander Jovanovic (1989, p. 128) afirma que "o romance-enciclopédia é um exercício de construção/desconstrução da obra literária e, ao mesmo tempo, um sagaz questionamento dos limites da obra literária e do processo de leitura". Nesse sentido, de acordo com Umberto Eco (1998, p. 193), a "descrição complexa" de elementos é atributo da enciclopédia. Por isso, o autor a adjetiva como labiríntica para predicar e para referenciar a suposta aparência "desordenada" desta, haja vista que são oferecidos conjuntos de elementos que não estão necessariamente relacionados entre si. A desordem destacada é semântica, mas há também o imbricamento estrutural, na medida em que as forças remissiva e relacional quebram a concepção de totalidade e harmonia. Por possuir uma lógica, uma semântica fragmentária, Umberto Eco (1989, p. 338) aproxima a estruturação enciclopédica do labirinto: "O projeto de uma competência enciclopédica é regido por uma metafísica (muito influente) que se pode exprimir através da metáfora do labirinto (que por sua vez remete ao modelo topológico da rede polidimensional)".

Um dos elementos principais da discussão do romance como enciclopédia aberta, para Italo Calvino (1990, p. 121), é reconhecê-lo "como método de conhecimento, como cadeia de conexões entre os fatos, entre as pessoas, entre as coisas do mundo". Todavia, é preciso distinguir como essa teia se configura. Afinal de contas, o que é uma rede? É um padrão de organização, de interação e de abundância de caminhos, isto é, de costura de relações possíveis entre os pontos (nodos) e um centro ou centros por intermédio da exploração imaginativa do espaço-tempo dos fluxos. Pela perspectiva de Umberto Eco (1991), enquanto uma hierarquia oferece caminho único de $\mathrm{A}$ para $\mathrm{B}$ para $\mathrm{C}$, dessa forma, ela é dicionarista; já a rede oferece múltiplas conexões, logo, se caracteriza como enciclopédica. Nesse sentido, segundo Umberto Eco (1991, p. 115), o rizoma deve ser entendido como sinônimo de distribuição, por sua vez, como imagem definidora da enciclopédia contemporânea, porque ajuda quer na visualização, quer na criação da ligação entre os pontos interpretativos díspares:

[...] cada ponto do rizoma pode ser unido e deve sê-lo com qualquer outro ponto e, com efeito no rizoma não há pontos ou posições, mas apenas linhas de conexão; um rizoma pode ser quebrado num ponto qualquer e recomeçar seguindo a própria 
linha; é desmontável, invertível; uma rede de árvores que se abre em toda direção pode produzir rizoma, o que equivale a dizer que em cada rizoma pode ser retalhada uma série indefinida de árvores parciais; o rizoma não tem centro.

Eis, pois, na imagem abaixo, o sentido do adjetivo aberto e a configuração da rede distributiva:

\section{IMAGEM 1 - Rede distributiva}

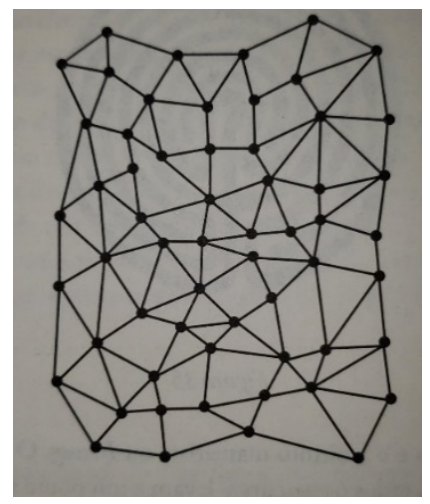

Fonte: Eco (2013, p. 62)

Italo Calvino (1990) não enumera os traços constitutivos dessa organização romanesca. Contudo é possível identificar e enumerar quais pontos qualificam a poética da arquitetura enciclopédica e os expomos, em suma, como mecanismo para facilitar o uso deste método: a) o romance como método de conhecimento, como rede de conexões capaz de ligar fatos, pessoas e coisas; b) a desordem como negação da teleologia e criadora da feição labiríntica; c) o excesso de informação e a ligação entre pontos espaços-temporais como tentativa de recriar esteticamente o processo mnemônico; d) a acumulação do pormenor; e) o inacabado e o aberto; f) o fracasso da ambição de propósitos do romance como enciclopédia aberta oriundo do projeto maximalista de abarcar tudo, desde o micro até o macro, visando a dar conta de toda a realidade.

Feitas essas ponderações, agora questionemos: Como esse campo teórico impacta a leitura crítica da produção de Agustina Bessa-Luís? Se a multiplicidade se apresenta como valor basal do romance como enciclopédia aberta, como isto se sucede na escrita da autora lusa? 


\section{Enciclopédica Agustina}

Em "Da literatura como interpretação de Portugal", Eduardo Lourenço (2016) argumenta que a recorrente pergunta "o que é Portugal?" fundamenta parte significativa da literatura lusa dos últimos 150 anos. Enxergarmos esse questionamento como mecanismo desencadeador da produção enciclopédica de Agustina Bessa-Luís. Em outras palavras, a busca do é do ente Portugal fomentou extenso conjunto literário que retoma e repensa aspectos históricos, filosóficos e estéticos. Alicerçado nesse ponto, destacamos o motivo do conjunto literário de Agustina Bessa-Luís ser entendido como o epicentro de um fenômeno estruturante da cultura portuguesa, com o seu ímpeto e necessidade inventariantes e o caráter enciclopédico. Se Portugal não se fez um país de filósofos, como acreditava Antero de Quental, Eça de Queiroz, Oliveira Martins, ou seja, a geração dos vencidos da vida, por outro lado, construiu-se como uma pátria de historiadores e de autores preocupados em guardar literariamente a cultura lusíada para, assim, demarcar peculiaridades.

Ao longo de quase setenta obras, mais de três mil páginas de ponderações críticas, além da produção dramática, a romancista retoma sistemas filosóficos, reflexões acerca da história e estabelece sua teoria do romance representada no conceito de memória do amor. Conceito esse que retoma a importância da memória, do inventário de existências e de coisas do mundo como uma das funções-chave da tessitura romanesca. A partir dos finais da década de 70, quando assinala na introdução à Santo António, a biografia sobre o santo, a necessidade de adotar lentes mais relativistas para a discurso histórico, nota-se como a retomada da História portuguesa e ocidental simboliza uma das vertentes principais de uma extensa reflexão sobre o país, cuja consequência é a escrita de uma enciclopédia ficcional e o inventário de Portugal. Ao investigar e inventariar aspectos da cultura portuguesa, a romancista efetiva um movimento que parte do micro (os objetos, a casa, a província) para o macro (a História da nação), manifestando, dessa forma, um traço importante daquilo que entendemos por romance como enciclopédia aberta.

Assim, podemos dizer que inventariar, arquivar e preservar são ações presentes nos romances de Agustina Bessa-Luís, na medida em que há o claro anseio de registrar e de representar uma sociedade rural do Norte de Portugal, em processo de transformação, tal como ocorre em $A$ Sibila. Mas há também a retomada dos mitos fundantes da nação através do processo de revisitação histórica, conforme acontece em Adivinhas 
de Pedro e Inês. A revisitação se efetua, no caso dos romances históricos recentes, para apontar os silêncios da História, e não para (re)afirmar a narrativa unitária cerzida pela historiografia oficial a partir dos relatos de guerras e dos feitos de grandes homens (reis) para a construção da História da pátria.

Quando aponta os seus assuntos principais, Agustina Bessa-Luís vai ao encontro desses anseios: "O que tenho como motivo preciso? Os interiores das casas, o vestir, o andar, as palavras, os gatos" (BESSALUÍS, 200, p. 23). Ter esses dados (também) como motivos não deixa de ser uma forma de preservá-los e de fazer com que a factualidade de cada um não seja "história oca". Os muitos narradores agustinianos e, consequentemente, suas narrativas esmiúçam um contexto que deixou de existir, mas que precisa ser registrado. Um dos casos mais emblemáticos é $A$ Sibila, pois a autora mostra a realidade em transição, os espaços da província, a vida prosaica com "seus membros, serviços, animais, objetos, afazeres, situações, comidas, hábitos e hierarquias" (MACIEL, 2009, p. 71). A obra funciona como uma espécie de arquivo de um contexto que desaparece, portanto, deve e precisa ser arquivado e registrado por uma pluralidade de vozes.

Com essa escolha compositiva, a romancista tenta dar conta de uma realidade complexa que não pode ser exposta por nenhuma voz privilegiada, mas por um conjunto de olhares. Salvar o passado do esquecimento significa recolhê-lo, almejando preservá-lo para as futuras gerações. Este, inclusive, era o anseio dos enciclopedistas. $\mathrm{O}$ ímpeto inventariante verifica-se pelo recenseamento das paisagens dos homens e mulheres nortenhos e pelo "arquivar a própria vida", segundo Philippe Artières (1998), como recolha literária da existência emocional e biográfica de si e dos entres próximos. Existem os movimentos de acumulação do pormenor, dos motivos íntimos particulares aliados ao inventário de mulheres, homens e coisas do mundo em sua "complexa estrutura dos afetos, obsessões e lembranças que definem o espaço dos seres" (MACIEL, 2009, p. 79). Esses afetos, obsessões e lembranças esculpem, assim, o "trabalho melancólico de inventariar perdas e ruínas" (MACIEL, 2009, p. 78).

Romances como enciclopédia aberta possuem uma configuração estrutural que estratifica a arquitetura textual maximal em vários níveis compostos por itens não lidos em chave polifônica, mas sim poliândrica. Mais do que vozes discordantes apresentadas em igualdade, há camadas teóricas, outras de ponderações metatextuais e algumas de teor 
filosófico, assim como conceituações e inquirições acerca de diferentes modelos interpretativos, como a "fronteira da arte pós-pós-moderna". $\mathrm{O}$ dodecaedro desmontado ilustra essa multiangulamento e por essa razão, em A construção do romance, Carlos Ceia (2007, p. 96) aponta a aparência poliândrica do romance como enciclopédia aberta:

Tais como as plantas poliândricas que têm muitos estames, um romance poliândrico será aquele que possui várias camadas ou tecidos narrativos que se combinam livremente entre si [...]. Tratase de fazer variar tanto as focalizações como os géneros, os subgéneros, os textos e os sub-textos, as histórias e as não histórias num mesmo romance.

Em Estética e personagens nos romances de Agustina BessaLuis, Catherine Dumas (2002, p. 15) enfatiza que uma das maiores problemáticas de ordem semântico-estrutural da escrita ficcional da romancista finca-se no "levar o gênero romanesco até os seus limites, questionando-o sem trégua". Ao apontar as potencialidades e as fronteiras do discurso literário, o romance como enciclopédia aberta deixa ao leitor a percepção e a escolha daquilo que considera importante à proporção que estabelece inventários de ordens diversas. À medida que intensa recolha acontece, operam-se, no mesmo estrato textual, as atividades críticas e teóricos que timbram a dicção romanesca agustiniana. A Ronda da Noite, publicado em 2006, último romance escrito pela autora, consiste em uma grande reflexão sobre a pintura enquanto acontece a narrativa de Martinho Nabasco. Há nessa obra, mas em muitas outras, notável entrecruzamento entre os níveis ensaístico, teórico e ficcional, que fazem com que a romancista teste os limites do gênero romanesco. Na relação entre teoria e ficção, aquela pode funcionar como comentário desta. Mas nem sempre. As artinhas dos narradores agustianos, seus torneios argumentativos requerem atenção, cuidado e esforço. Estamos diante de romanções exigentes, retomando Leyla Perrone-Moisés (2016).

Com a estruturação poliândrica, multifacetada, Agustina BessaLuís esgarça a definição de romances e produz labirínticos caminhos que se constroem e se destroem em questão de instantes. Nesse percurso, verificamos uma amplitude temática distendida sob uma técnica de composição que podemos chamar de escrita entre parênteses, pois o constante uso desse sinal pela romancista marca a adoção da pluralidade de vozes e de hipóteses, representando a materialidade textual da 
multiplicidade. Na amplitude da busca sobre o que é Portugal, sobressai a impossibilidade da autora em responder definitivamente à interrogação apontada por Eduardo Lourenço (2016). Questionar e apresentar dados da cultura e da História portuguesas por ângulos distintos produzem o inventário imperfeito de um país e Agustina Bessa-Luís leva esse impulso ao máximo. Mas, por intermédio da reflexão sobre Portugal, a ficcionista interroga - aumentando a extensão dos arcos reflexivos - traços da condição humana, por exemplo, a constatação da temporalidade, sendo que o tempo e a memória representam dois assuntos elementares.

$\mathrm{O}$ desejo de (re)colher todo o saber de um povo funciona como um dos modos de compreensão da sua extensa produção, pois o ímpeto inventariante dos entes constituintes de uma nação assimila-se à "paixão pelo conhecimento", na expressão de Álvaro Manuel Machado (1984, p. 77). Paixão pela gnose como mecanismo psíquico a ser desbravado, mas também como determinante moral - assunto pelo qual a escritora nutre interesse -, assim como paixão pelo conhecimento dos elementos formadores dos Homens, como a temporalidade e a memória. No discurso crítico sobre a pintura presente em A Ronda da Noite, Agustina Bessa-Luís aproxima estética literária e estética pictórica a partir desses elementos. Nesse processo, ganha destaque a importância da dúvida perante as certezas. Se a paixão pelo saber oferta um sistema filosófico, uma teoria matemática, é possível dizer que os narradores de Agustina Bessa-Luís realizam movimento similar, em romances que dão forma "à preocupação do sentido" (LOURENÇO, 1994, p. 309). Mas a pulverização de perguntas conduz a outros saberes e a outras vozes, o que faz com que a "preocupação do sentido" continue nessa espera, sempre em suspenso, sem culminar em afirmações. A bruma filosófica e o excesso conduzem ao impedimento de fechamento, o que evidencia aqui a força da abertura destacada por Italo Calvino (1990). O romance como enciclopédia aberta se caracteriza, assim, como manifestação da multiplicidade de interpretações e o ímpeto enciclopédico enquanto aspectos qualificadores do conjunto literário da romancista. Nessa perspectiva, a autora apresenta

o mundo como ambiguidade, [tendo] de enfrentar, em vez de uma só verdade absoluta, muitas verdades relativas que se contradizem (verdades incorporadas em egos imaginários chamados personagens), [tendo] portanto como única certeza a sabedoria da incerteza, isso não exige menos força (KUNDERA, 2016, p. 15). 
A "sabedoria da incerteza" ou a certeza da incerteza, dito de outra forma, enseja a multiplicação de interrogações, o labiríntico ficcional, o ziguezagueante jogo entre perguntas e contraperguntas. Em uma produção que prima pela pluralidade, esse fato tem como consequência a "disseminação de hipóteses não convertíveis à totalidade", na concepção de Silvina Rodrigues Lopes (1992, p. 33). No prefácio à Agustina por Agustina, Artur Portela (1986, p. 8) destaca esse dado quando sublinha que "há respostas de Agustina que são perguntas, e não, claro, ao entrevistador". Acentua-se, diante disso, o entendimento de que as inquirições têm mais efeito retórico do que desejo de resposta. Assim, a argumentação da autora fomenta um constante movimento desestabilizador. Neste contexto, a "paixão pelo conhecimento" e "a preocupação do sentido" se coadunam à urgência de questionar e de mobilizar definições à medida que, proporcionalmente, indefinições e aberturas se alastram pela intensificação da amplitude de vozes. Ao transformar respostas em outras interrogações, o narrador de $A s$ pessoas felizes (1975), por exemplo, revela que "não há uma resposta que não se possa transformar em pergunta" (BESSA-LUÍS, 1975, p. 97). A multiplicação e a interrogação constroem o caráter hiperbólico, maximalista, labiríntico e aberto da enciclopédia agustiniana. Pulverizar inquirições representa valorizar a lógica aditiva não adversativa.

Se pensarmos essas dimensões em um romance como A Sibila (1954), obra fundamental da autora, vamos ver que Quina é uma personagem feminina pioneira, uma mulher que gerencia uma propriedade rural num meio eminentemente dominado pela ordem patriarcal, pelo pensamento provinciano e pela importância dada aos valores do sangue e do solo. Uma teia de predicados a qualifica, assim, as visões dos entes da narrativa a respeito de Quina se multiplicam. Nesse romance, Agustina Bessa-Luís refuta o indivíduo como unidade autônoma e coerente. A escritora não as representa como puras categorias quer emocionais, quer sociológicas. A contradição denota proeminente caminho que Agustina Bessa-Luís escolhe para falar sobre a humanidade.

Em A Corte do Norte (1986), o destino da personagem Rosalina de Sousa é uma incógnita. Não se sabe se ela caiu das falésias e morreu, ou se foi morta por seu marido e enterrada, ou se fugiu, ou se mudou de nome e assumiu outra personalidade. Todas essas possibilidades constroem uma rede de adições plausíveis, permitidas pelo conjunto de interpretações, graças à semântica enciclopédica, a partir do uso da 
conjunção alternativa "ou”, que viabiliza a criação do cariz enciclopédico pela amplificação de semânticas. Essa trama é um bom exemplo de como, em Agustina Bessa-Luís, "circula uma saudável paixão pela desordem, uma espécie de atordoamento que nos leva a repensar as visões que temos do mundo e a tentação de segurança e ordem que não deixamos de perseguir" (HELENO, 2002, p. 29). Estamos diante de uma autora que privilegia a multiplicidade pela fragmentação e pela desordem e, nessas circunstâncias, repensa a construção do conhecimento e da informação. Por conseguinte, isso faz com que o "discurso exigente" da ficcionista portuguesa exija também o do leitor. Este vê-se obrigado a criar a teia multidimensional e incompleta das múltiplas informações oferecidas por vozes heterogêneas. Assim, a teia, por sua estrutura, constitui um espaço que também prende alguém.

A imagem do labirinto ilustra qualidades da formulação da romancista, sendo esta formada por intrigas construídas por emaranhados e imbricados caminhos, pelos constantes desvios da narrativa que não chega a um centro. Basta observar, nesse sentido, o fato de que os seus romances terminam sempre deixando algo por dizer. Eduardo Lourenço (1994, p. 161) entende que, na produção literária da autora, se vislumbra um "universo sem verdadeiro começo nem fim". Seguindo essa linha de raciocínio, o que não tem "verdadeiro começo nem fim" não possui centralidade. Por isso, o aforismo, em Agustina Bessa-Luís, consoante com Silvina Rodrigues Lopes (1990, p. 110), passa a ter um uso paradoxal, posto que representa o desejo de totalização diante de um texto que corrobora a sua impossibilidade pelo "inacabamento essencial" dos Homens. Quando tece "romances caudalosos" (LOPES; SARAIVA, 1982, p. 1101), a escritora revela que existir implica caminhar na falta, pois, de acordo com seu pensamento, "viver e lançarmo-nos nos espaços vazios que a obra humana, como um destroço vai ocupar" (BESSA-LUÍS, 1982, p. 105-106). Assim, o espaço vazio efetiva-se como o local da vertigem, do encontro com o nada ou com o precipício.

A aparência desordenada (labiríntica) contesta o pensamento monolítico e holístico. Conforme elucida Italo Calvino (1990, p. 132): "Há a obra que corresponde em literatura ao que em filosofia é o pensamento não sistemático, que procede por aforismos por relâmpagos punctiformes e descontínuos". O labirinto textual altera a fluência narrativa. Ao falar inicialmente de uma personagem, passa-se a narrar as conexões desta com o lugar, com a história, com os objetos e a ligação 
desse lugar, desses objetos com outros seres que se interseccionam com esse ser primeiro que estava a ser narrado, e assim por diante, em um constante processo de acréscimo que gera o caráter hiperbólico e de desordem de sua escrita.

A desordem é então um fenómeno de abundância. Agustina não se cansa de o mostrar nos seus textos, misturando a espessura do passado com o rumor do presente. É preciso orientarmo-nos no caos do mundo; é preciso descobrir filiações, similitudes, parentescos e pôr assim, a analogia - como semelhança e como modelo heurístico - a funcionar. (HELENO, 2002, p. 24)

Mesmo sem tocar na ideia do romance agustiniano como enciclopédia aberta, José Manuel Heleno (2002) pontua alguns fundamentos discutidos até agora (abundância de informação e desordem semântica, por exemplo), o que reitera o argumento de que a organização estrutural da autora pode ser entendida como rede distributiva que põe em interação elementos multíplices. Esse tipo de romance conecta à primeira vista elementos discrepantes ou que estavam em campos semânticos completamente distantes, ao passo que diminui a relação espaço-temporal daquilo que parecia distante, conforme destaca o crítico no fragmento supracitado. A rede não deixa de ser, portanto, uma forma de interação entre diferentes espaços e tempos.

Em Agustina Bessa-Luís, os dados se interconectam. O aparentemente desordenado ganha ordem e a unidade do fragmentado vem à tona, mas nunca a totalidade. Nossa perspectiva alinha-se à de Álvaro Manuel Machado (2009, p. 31) para quem "tudo em Agustina se liga, misteriosamente, também tudo acaba por ficar inacabado, inexplicável, suspenso no tempo e no espaço". O próprio conceito de enciclopédia invoca essa dimensão, uma vez que carrega a noção de círculos interrelacionados, ou seja, de elementos conectados. Diante disso, o romance como enciclopédia aberta tem uma "estrutura acumulativa, modular, combinatória" (CALVINO, 1990, p. 134). Dessa maneira, argumentar sobre esse tipo de construção romanesca significa buscar a linha invisível que conecta um ao outro e, em último grau, estabelece a coerência do vasto conjunto literário. Em suma, existe uma busca incansável que não se finda, uma progressão que não avança à medida que a matéria se fragmenta. Desse modo, as voltas e reviravoltas, a multiplicidade de níveis, de vozes, de informações narrativas, o hiperbólico, a amplificação, a semântica 
enciclopédica e a visão do mundo como absurdo fazem com que o leitor tateie as paredes de um labirinto. Como se acontecesse a negação do modelo moderno, da centralização, da progressão epistêmica e do espírito. Daí a conclusão de José Manuel Heleno (2002, p. 31): “Grande parte das narrativas de Agustina Bessa-Luís são helicoidais ou espiraladas”. Círculos e níveis sucessivos espiralados criam a percepção de incessante retomada.

Perspectivando a extensa obra de Agustina Bessa-Luís, portanto, percebe-se a ênfase sobre o projeto hiperbólico, o método de amplificação, fragmentação e associação responsáveis pela verve maximalista do romance como enciclopédia aberta. E, para tanto, essa escolha composicional pode partir do micro (objetos, pequenos espaços, narrativas, cacos e detritos da existência) para o macro (grandes paisagens, acontecimentos históricos e personalidades históricas). Essas duas fontes de narrativas são espiraladas, de modo que os motivos de Agustina Bessa-Luís vão do vestir, do andar, das casas rurais à historiografia. Aqui, a multiplicidade afasta a totalidade e, assim, outros importantes aspectos vêm à tona, dentre os quais a certeza da incompletude, tanto da obra quanto da interpretação, e a persistência do ímpeto inventariante, sempre latente em quem almeja levantar toda a informação existente, mas sabe, igualmente, dessa impossibilidade.

\section{Considerações finais}

Conforme argumentamos ao longo deste ensaio, as reflexões de Italo Calvino (1990) sobre a multiplicidade e o romance como enciclopédia aberta fomentam um proveitoso mecanismo crítico e analítico acerca da produção agustiniana. Por diferentes ângulos, a concepção de sistemas ordenadores centrados aparece colocada em xeque pela escritora e pelo romance enciclopédico. O leitor de Agustina BessaLuís deve ver a existência como "teia de relações" e como rede capaz de ligar diferentes tempos e espaços. Ao longo de décadas de produção, a autora construiu uma grande enciclopédia sobre Portugal (mas não só) ao retomar e questionar os mais variados elementos constitutivos do modo de ser português, os aspectos da paisagem e da realidade de um povo, os mitos, as personalidades e os acontecimentos históricos, evocando uma série de elementos que ajudaram a fomentar e a construir essa identidade, à proporção que também enfatiza os "desconhecidos" da História.

Obra extensa e ampla como a de Agustina está mergulhada no "inconsciente coletivo" de séculos de recolha, análise e inventário da 
cultura e História portuguesas. A produção agustiniana, portanto, prendese a um contexto maior - alicerça-se numa espécie de zeitgeist de sua pátria. Neste caso, nota-se que o romance como enciclopédia aberta tem uma "estrutura acumulativa, modular, combinatória" (CALVINO, 1990, p. 134). Cada texto agustiniano, em sua unidade, ajuda a formar a imagem incompleta da cultura lusitana, mas também cada uma delas constitui um novo tomo, uma outra leitura para essa mesma realidade que almeja mostrar o absurdo e o contraditório, observados desde a escrita da História ao traço ficcional movente do real. No acumular das respostas, das hipóteses, das possibilidades e, consequentemente, das dúvidas, o romance como enciclopédia aberta lida com uma grande gama de fatos e seus subsequentes não fechamentos. Assim, o inacabado nasce do desejo de representar tudo e de dar conta de um universo, ocasionando uma extensão maximalista e hiperbólica.

Os heterogêneos volumes da enciclopédia romanesca sobre a cultura lusíada escrita por Agustina Bessa-Luís permitem retomar peças deste grande mosaico que é Portugal. Assim sendo, temos fatos históricos, grandes personalidades e traços essenciais de uma cultura não apenas destacados, mas também colocados entre parênteses. Na evocação dos elementos que compõem a narrativa do país, põem-se em xeque esses mesmos fatos, essas mesmas verdades, quer sejam históricas, quer sejam puramente ficcionais. Expande-se, dessa forma, a capilaridade de uma estrutura fechada em si para dar forma à multiplicidade como elemento constitutivo do romance enciclopédico e da poética da autora.

Em um trabalho hercúleo, Agustina Bessa-Luís inventaria quase tudo para compor uma imagem da cultura lusitana e distinguir a impossibilidade de um fechamento absoluto. Nessa dinâmica, a força do termo "aberta" aponta que, para além do trabalho de Hércules, há também o de Sísifo por meio de uma verdadeira "ambição de propósitos" (CALVINO, 1990, p. 127) capaz de movimentar e fomentar a composição do extenso conjunto literário enciclopédico agustiniano.

\section{Referências}

ABAGnANO, N. Dicionário de filosofia. Tradução de Alfredo Bosi. 6. ed. São Paulo: WMF Martins Fontes, 2015.

ARTIÈRES, P. Arquivar a própria vida. Arquivos pessoais. Revista Estudos Históricos, Rio de Janeiro, v. 11, n. 21, p. 9-34, 1998. 
BESSA-LUÍS, A.; PORTELA, A. Agustina por Agustina. Lisboa: Dom Quixote, 1986.

BESSA-LUÍS, A. Contemplação carinhosa da angústia. Org. Pedro Mexia. Lisboa: Guimarães, 2000.

BURKE, P. Uma história social do conhecimento I: de Gutemberg a Diderot. Tradução de Plínio Dentzien. Rio de Janeiro: Zahar, 2003.

CALVINO, I. Seis propostas para o próximo milênio: lições americanas. 2. ed. Tradução de Ivo Barroso. São Paulo: Companhia das Letras, 1990.

CEIA, C. A construção do romance: ensaios de literatura comparada no campo dos estudos anglo-portugueses. Coimbra: Almedina, 2007.

DUMAS, C. Estética e personagens nos romances de Agustina BessaLuís: espelhismos. Porto: Campos das Letras, 2002.

ECO, U. Da árvore ao labirinto. In: . Da árvore ao labirinto: estudo histórico sobre o signo e a interpretação. Tradução de Maurício Santana Dias. Rio de Janeiro: Record, 2013. p. 13-101.

ECO, U. Dicionário versus enciclopédia. In: . Semiótica e filosofia da linguagem. Tradução de Mariarosaria Fabris e José Luiz Fiorin. São Paulo: Ática, 1991. p. 63-140.

ECO, U. O antiporfírio. In: . Sobre os espelhos e outros ensaios. Tradução de Beatriz Borges. Rio de Janeiro: Nova Fronteira, 1989. p. 316-341.

ECO, U. O ornitorrinco entre dicionário e enciclopédia. In: . Kant e o ornitorrinco. Tradução de Ana Thereza B. Vieira. Rio de Janeiro: Record, 1998. p. 191-235.

FERNANDES, M. L. O Narciso no labirinto de espelhos: perspectivas pós-modernas na ficção de Roberto Drummond. São Paulo: Cultura Acadêmica, 2011.

HAN, B.-C. Hiperculturalidade: cultura e globalização. Tradução de Gabriel Salvi Philipson. Rio de Janeiro: Vozes, 2019.

HELENO, J. M. Agustina Bessa-Luís: paixão da incerteza. Lisboa: Editora Fim de Século, 2002.

JOVANOVIC, A. O Dicionário Kazer: as múltiplas leituras de um texto ou a construção/desconstrução da obra literária. Revista USP, São Paulo, 
n. 1, p. 128-131, mar./abr./maio 1989. DOI: https://doi.org/10.11606/ issn.2316-9036.v0i1p128-131

KUNDERA, M. A arte do romance. Tradução de Teresa Bulhões de Carvalho Fonseca. São Paulo: Companhia das Letras, 2016.

LOPES, Ó; SARAIVA, A. J. História da Literatura portuguesa. 12. ed. Porto: Porto Editora, 1982.

LOPES, S. R. Agustina Bessa-Luis: as hipóteses do romance. Rio Tinto: Editora Asa, 1992.

LOURENÇO, E. A indomável. Ler, Lisboa, n. 76, p. 40, jan. 2009.

LOURENÇO, E. O canto do signo: existência e literatura (1957-1993). Lisboa: Presença, 1994.

LOURENÇO, E. O labirinto da saudade: psicanálise mítica do destino português. Rio de Janeiro: Tinta da China, 2016.

MACHADO, Á. M. Agustina Bessa-Luís: o imaginário total. Lisboa: Dom Quixote, 1983.

MACIEL, M. E. As ironias da ordem: coleções, inventários e enciclopédias ficcionais. Belo Horizonte: Editora da UFMG, 2009.

MATTOS, Franklin. A cadeia secreta: Diderot e o romance filosófico. São Paulo: Cosac \& Naify, 2004.

PAMUK, O. O romancista ingênuo e o sentimental. Tradução de Hildegard Feist. São Paulo: Companhia das Letras, 2011.

PERRONE-MOISÉS, L. Mutações da literatura no século XXI. São Paulo: Companhia das Letras, 2016.

POMBO, O. O círculo dos saberes. Lisboa: Instituto de Filosofia, 2012.

SOUZA, M. das G. de. Círculo dos conhecimentos. In: DIDEROT, D.; D'ALEMBERT, J. Enciclopédia: discurso preliminar e outros textos. Tradução de Fulvia M. L. Moretto. São Paulo: Editora UNESP, 2015. p. 13-26.

Recebido em: 17 de outubro de 2020.

Aprovado em: 25 de janeiro de 2021. 